Proc. Indian Acad. Sci. (Earth Planet. Sci.), Vol. 94, No. 2, July 1985, pp. 111-115.

(C) Printed in India.

\title{
Anomaly map of $Z$ component of the Indian sub-continent from magnetic satellite data
}

\author{
M G ARUR, P S BAINS and JEEVAN LAL \\ Survey of India Geodepic and Research Branch, Dehra Dun 248001 , India \\ MS received 30 November 1983; revised 19 February 1985
}

\begin{abstract}
An anomaly map of the $Z$ component has been produced for the region of the Indian sub-continent for the first time by the Survey of India using MAGSAT data. Data of thousands of kilometres of satellite tracks of varying altitude have been reduced to a common elevation of $400 \mathrm{~km}$ by removing the external field and linear trend. The entire data was plotted on a map of 1:6 M and mean values of $2^{\circ} \times 2^{\circ}$ blocks then accepted for contouring. $A$ prominent magnetic low is reflected over the Himalayas and a prominent high over the Indian peninsula. The dividing line of positive and negative anomalies between the Himalayas and Deccan Traps falls along the Narmada lineament.
\end{abstract}

Keywords. Anomaly map; $Z$ component; MAGSAT data; magnetic low; magnetic high; Narmada lineament.

\section{Introduction}

In recent years, it has been realised that crustal magnetic anomalies exist which are of longer wavelengths than those found by exploration geophysicists and that these longer wavelength ( $>150 \mathrm{~km}$ ) anomalies are indicative of geologic and tectonic features in the deep crust (Pakiser and Zietz 1965; Zietz et al 1966; Shuey et al 1973; Hall 1974; Krutikhovskaya and Pashkevich 1977). Regan et al (1975) and Langel et al (1980) demonstrated that long wavelength lithospheric anomalies could be mapped successfully from satellites. Such a map showed a global distribution of anomalies of about $500-3000 \mathrm{~km}$ scale size which were never before mapped and whose very existence, in most cases, was discovered for the first time. Although such maps are distorted by variation in altitude over the data set and by contamination from magnetospheric field, Regan et al (1975) were able to demonstrate that the probable source of the anomalies is indeed the lithosphere. The map which was derived from data from the Polar Orbiting Geophysical Observatories (POGO), 2, 4 and 6 satellites showed a magnetic 'low' over the Himalayas and a 'high' over peninsular India.

In the present investigation, an anomaly map for the $Z$ component has been prepared based on MAGSAT data reduced for a common elevation of $400 \mathrm{~km}$.

\section{Limitations of satellite data}

One of the principal limitations of anomaly mapping with satellite data is that only large features are resolvable. Langel and Thorning (1982) indicate that the resolution of 
the POGo data is in the $250-500 \mathrm{~km}$ range. MAGSAT was designed to increase this resolution to $150-300 \mathrm{~km}$ by acquiring data at lower altitudes. The altitude range for the POGO spacecraft is $400-1510 \mathrm{~km}$; that of MAGSAT is $200-550 \mathrm{~km}$. The MAGSAT data were acquired between November 1979 and June 1980.

POGO satellites data provided a data set of earth's total intensity while MAGSAT collected data on vector components also.

\section{Method of deriving the anomaly map}

To derive the anomaly map, the earth's main field and the fields due to external currents have been accounted for by the procedure developed by Regan et al (1975), Mayhew (1979), and Langel et al (1980). The investigations have been carried out, with the aid of MAGSAT data on quiet days made available by NASA on three data tapes covering the Indian region. The data tapes were decoded and the anomaly information was derived by subtracting the model values of the $Z$ component from that of observed $Z$ values at the varying satellite altitudes. From this data set the field due to magnetospheric currents was removed. For each satellite pass the values of $e$ (magnetic field due to external currents) and $i$ (magnetic field due to induced internal currents) have been accepted as given in NASA Technical Memorandum 82160 . The data set thus obtained was reduced to a common elevation of $400 \mathrm{~km}$ by the method described by Henderson and Cordell (1971). The linear trend from each pass was also removed during this reduction. The residuals so obtained would represent crustal anomalies. In this procedure, the data reduced from geographically coincident passes matched well. The map is madefrom all the passes with varying $K p$ index from 0 to 33 . The average value of all the points falling in each $2^{\circ} \times 2^{\circ}$ block was calculated. The individual values which differed by more than thrice the standard deviation of the mean from the initial block average were neglected. Langel et al (1982) also used a similar method and eliminated all points within each block which differ by more than twice standard deviation from the initial block average. New averages were computed and these mean values were contoured to derive the map at a contour interval of $5 \mathrm{nT}$ (nanotesla) on a scale of $1: 16 \mathrm{M}$. In the final map, the average number of points per block is 9 and total number of data points is 2198 from which 648 have been neglected. No adjustments have been made for the varying geomagnetic inclinations.

\section{The anomaly map}

Figure 1 shows the resulting MAGSAT crustal anomaly map of the $Z$ component of the Indian sub-continent bounded by the area $8^{\circ} \mathrm{N}$ to $36^{\circ} \mathrm{N}$ latitude and $64^{\circ} \mathrm{E}$ to $100^{\circ} \mathrm{E}$ longitude at contour intervals of $5 \mathrm{nT}$ and on a scale $1: 16 \mathrm{M}$. Amplitudes vary from +20 to $-27 \mathrm{nT}$. A prominent zero level in the north coincides more or less with the northern limit of the Indo-gangetic plain (upto central Nepal). The other zero contour coincides more or less with the southern limit of peninsular India. Figure 2 indicates the number of data points in each block, the mean of the values (with rejection and without rejection of data) in each block and the standard deviation of the mean. 


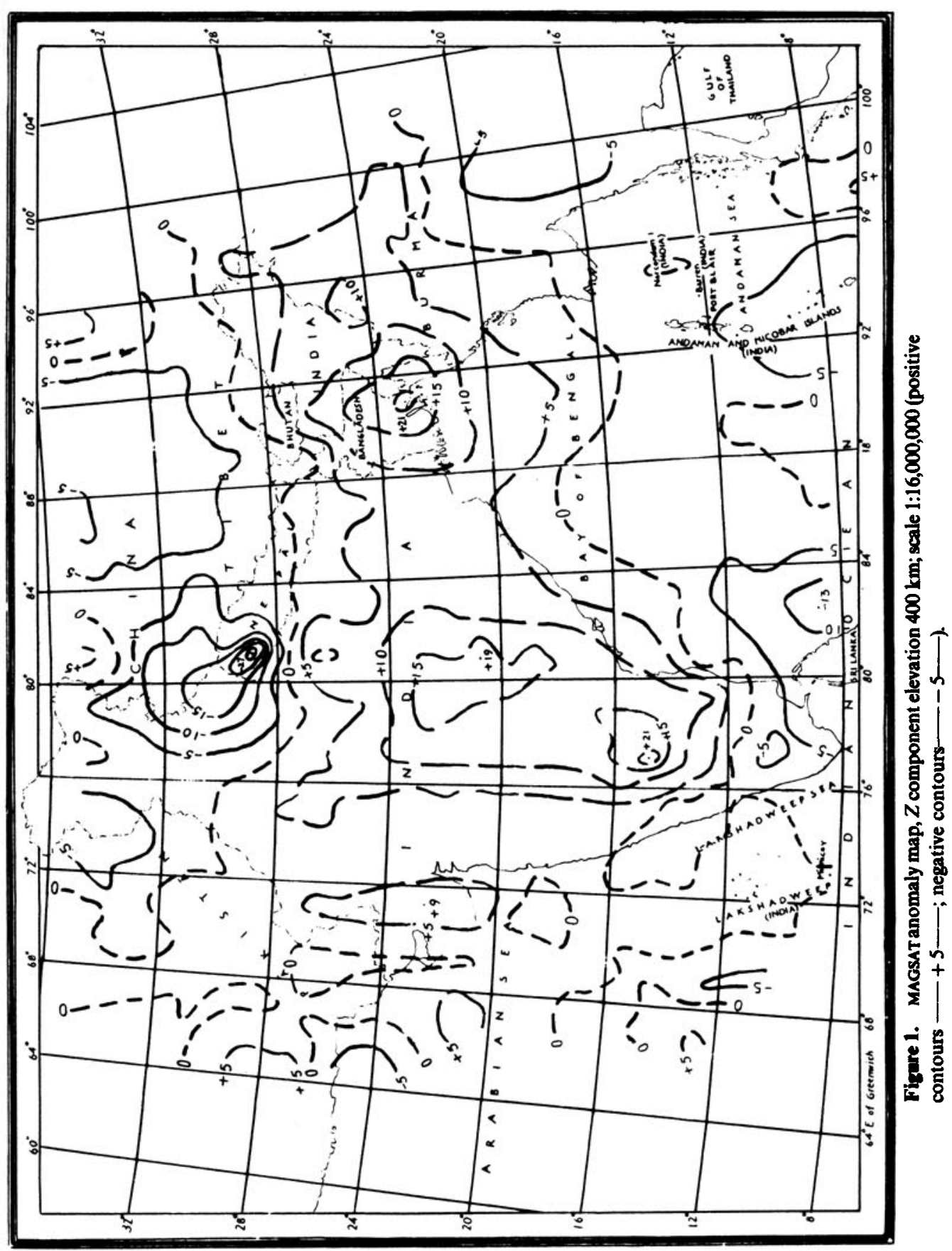




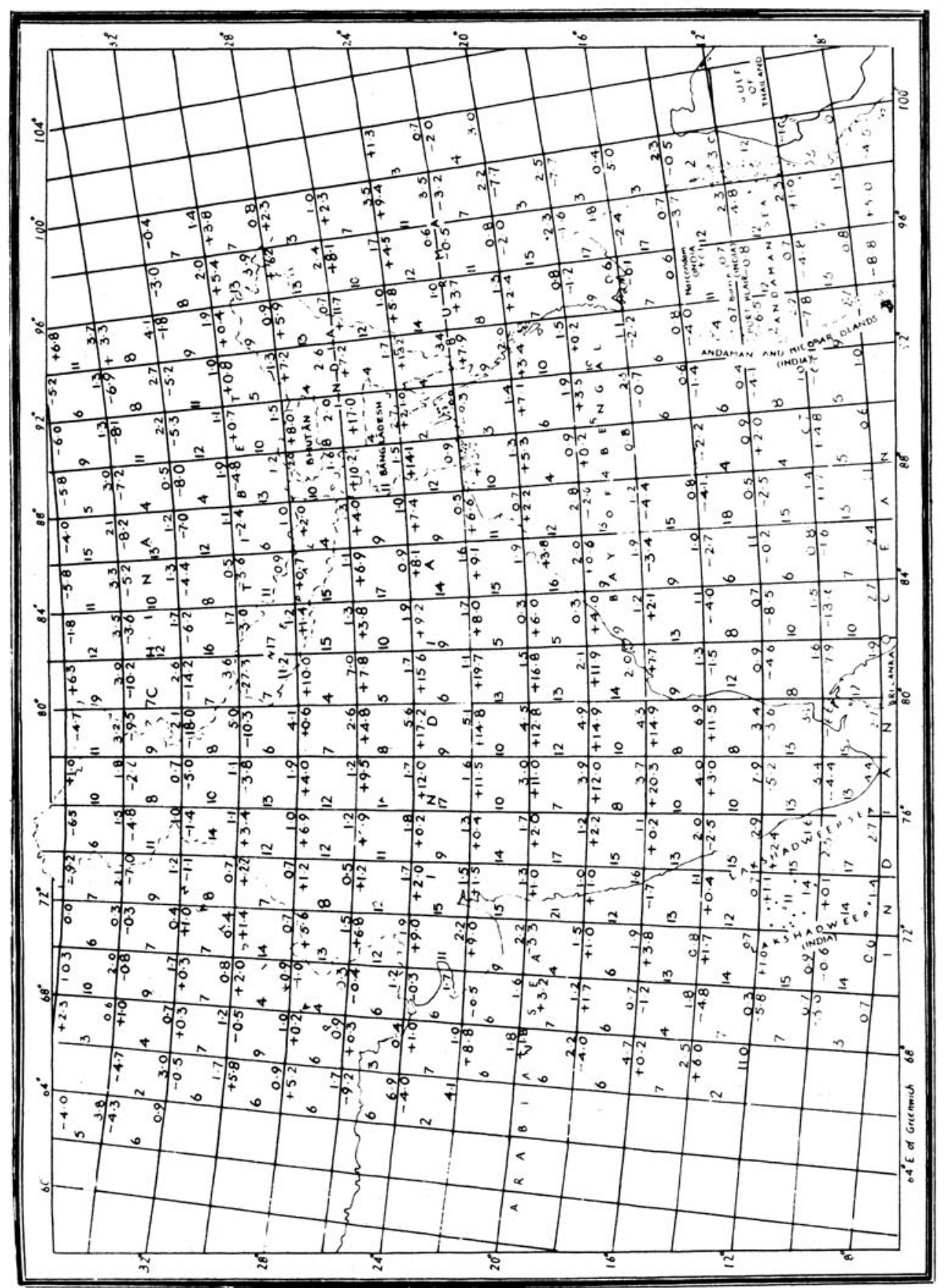

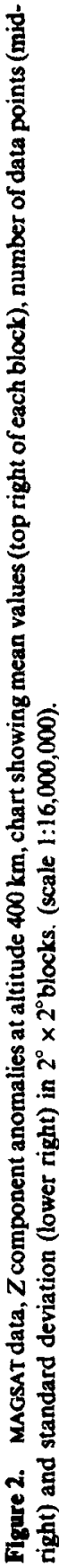




\section{Conclusions}

A $Z$ vector anomaly map of the Indian sub-continent has been prepared for the first time at an altitude of $400 \mathrm{~km}$. The anomalies vary from +20 to $-27 \mathrm{nT}$. Positive anomalies prevail over the Deccan Traps and Bangladesh and negative anomalies are predominent over the Himalayas and in the Indian Ocean. It is interesting to note that $Z$ anomalies obtained from ground data over the lower Himalayan region are generally positive, but both positive and negative over peninsular India.

If we compare our $Z$ anomaly map with the MAGSAT Scalar Anomaly map prepared by NASA, we notice that the NASA map also shows negative anomalies over western Nepal and positive anomalies over peninsular India and Bangladesh.

\section{Acknowledgements}

The authors are thankful to Dr B N P Agarwal of the Indian School of Mines for valuable guidance in developing the computer programme for the reduction of satellite data. The authors are grateful for the data, literature and computer programs received from NASA. The close support of the Surveyor General of India, Principal Investigator of the Project, Indian Space Research Organisation, the Indian Institute of Geomagnetism, Dr M N Qureshy of the Department of Science and Technology and the Oil and Natural Gas Commission for this research work is thankfully acknowledged.

\section{References}

Hall D H 1974 J. Geophys. 40403

Henderson R G and Cordell L 1971 Geophys. 36856

Krutikhovskaya Z A and Pashkevich I K 1977 Can. J. Earth Sci. 142718

Langel R A, Coles R and Mayhew M A 1980 Can. J. Earth Sci. 17876

Langel R A and Thorning L 1982 In Nares strait and the drift of Greenland: a conflict in plate tectonics (eds)

P R Dawes and J W Kerr (Meddr. Greenland, Geosci)

Langel R A, Phillips J D and Horner R J 1982 Geophys. Res. Lett. 9269

Mayhew M A 1979 J. Geophys. 45119

Naqvi S M, Divakara Rao and Hari Narain 1978 Tectonophysics 6323

Pakiser L C and Zietz I 1965 Rev. Geophys. 3505

Regan R D, Cain J C and Davis W M 1975 J. Geophys. Res. 80794

Shuey R T, Schellinger D R, Johnson E H and Alley L G 1973 Geology 1107

Zietz I, King E R, Geddes W and Lidiak E G 1966 Geol. Soc. Am. Bull. 771427 